\title{
Creating Virtual Spaces to Build Community Among Students Entering an Undergraduate Biomedical Engineering Program
}

\author{
Steven Higbee (1), ${ }^{1}$ Sharon Miller $(1),{ }^{1}$ Abigail Waterfill, ${ }^{1}$ \\ Kayla Maxey (iD, ${ }^{1}$ Julie Stella (iD) ${ }^{2}$ and Joseph Wallace (iD ${ }^{1}$ \\ ${ }^{1}$ Department of Biomedical Engineering, Indiana University-Purdue University Indianapolis, Indianapolis, IN, USA; and \\ ${ }^{2}$ Department of Technology Leadership and Communication, Indiana University-Purdue University Indianapolis, Indianapolis, \\ IN, USA
}

(Received 30 June 2020; accepted 20 July 2020; published online 20 August 2020)

\section{CHALLENGE STATEMENT}

Undergraduate biomedical engineering (BME) programs challenge students with rigorous and multidisciplinary curricula that integrate concepts from the life sciences, mathematics, and engineering. Furthermore, BME curricula often incorporate active and team-based learning methodologies, in addition to more traditional engineering problem solving. ${ }^{7}$ To succeed in such broad and challenging programs, students may depend on interactions with their peers, both in and out of the classroom. We have observed that the shared challenge of an undergraduate BME curriculum creates a strong sense of community among each cohort of students, and we fear that students who enter our program during the COVID-19 pandemic may miss out on the formative experiences that begin to build such a community.

Among the downsides of remote and blended learning models is the lack of face-to-face interactions that contribute to a sense of community among students. Such models may introduce risks for students, as psychological sense of community has been linked to perceived cognitive learning, ${ }^{10}$ persistence in degree programs, ${ }^{12}$ course satisfaction, ${ }^{6}$ and knowledge-sharing behavior. ${ }^{15}$ Many studies have reported efforts to enhance student engagement and sense of community in online and hybrid courses. Greater sense of community has been linked to increases in computer-mediated communication among students, ${ }^{3}$ instructor use

Address correspondence to Steven Higbee, Department of Biomedical Engineering, Indiana University-Purdue University Indianapolis, Indianapolis, IN, USA. Electronic mail: sjhigbee@iupui.edu of multimodal interactive learning environments and online social events, ${ }^{1}$ and instructor-moderated discussion boards and synchronous communication between students. ${ }^{2}$ In one survey focused on key strategies for building community in online courses, students ranked first the modeling of communitybuilding behaviors by the course instructor. ${ }^{14}$

At our large Midwestern public university, undergraduate engineering students must complete a mostly general first-year curriculum (i.e., introductory engineering, programming, mathematics, and science courses) before entering programs associated with individual engineering disciplines. Consequently, students in our undergraduate BME program are interspersed with students from varied STEM fields in their first-year courses before joining a roughly 40-student cohort that will take more than 15 BME courses together. Given the relatively small sizes of our student cohorts and the number of required courses, our students tend to form rich social connections with their classmates. In the first semester of our program, students must enroll in three courses: Introductory Biomechanics, Biomechanics Lab, and Introduction to Engineering Technical Reports (Fig. 1). Introductory Biomechanics is a lecture- and problem solving-based course that covers statics and mechanics of materials; Biomechanics Lab is a laboratory course that entails the application of mechanical principles to biological and synthetic materials; and Introduction to Engineering Technical Reports is a technical communication course organized around the writing of lab reports.

After the transition to online instruction in response to the COVID-19 pandemic, students in our program lamented the loss of connection to their peers, more so 
BME Coursework, First Year in Program (Sophomore)

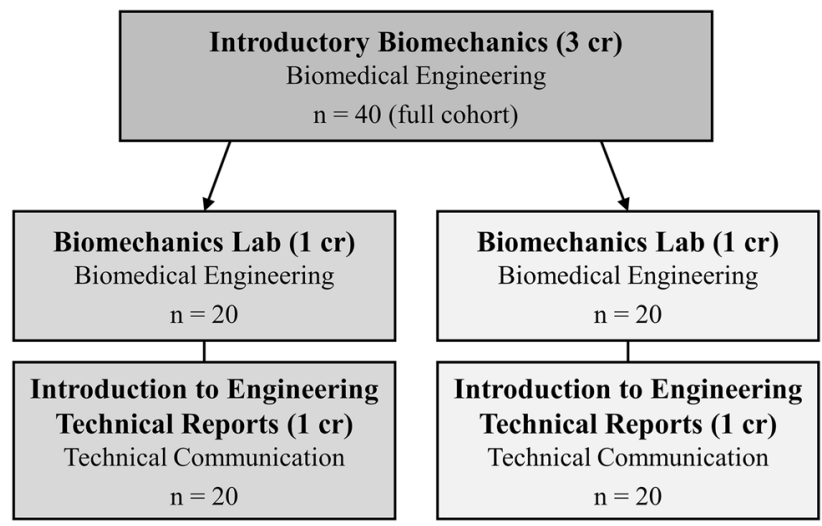

FIGURE 1. Students entering the undergraduate biomedical engineering program, after completing freshman engineering requirements, enroll in three connected courses that initiate the biomedical engineering curriculum. All students enroll in Introductory Biomechanics but split into paired cohorts for the associated laboratory and technical communication courses.

than diminished access to faculty, teaching assistants, or other resources. Fortunately, given that the semester was well underway when the transition occurred and few students in our courses were new to our BME program, we feel that students missed out on relatively few formative community-building experiences. This would not be the case for a fall semester of online instruction, however, so we must take action for the sake of our incoming class of undergraduate students. Our experience from spring 2020 and our review of the relevant literature suggest that we can be successful at building community among our new cohort of BME students, regardless of the mode of instruction.

\section{NOVEL INITIATIVE}

\section{Extending Virtual Collaboration Outside of Lecture to Build Departmental Culture}

The challenges of quickly shifting instruction online in the spring of 2020 presented instructors opportunity to both synchronously and asynchronously engage with students in a virtual environment. A campus-wide student survey found that $81 \%$ of student respondents agreed or strongly agreed that the learning management system (i.e., Canvas) was a useful resource when transitioning online. ${ }^{5}$ Additionally, BME instructors found that Canvas discussion boards and Zoom breakout rooms were quickly adopted by students and instructors alike, as alternate collaborative online tools. While efficient digital presence may have been lacking in the past, our department plans to extend the use of virtual collaboration tools used in the classroom to help build incoming BME student collaboration and departmental culture.

Specifically, we will employ virtual tools for community building for discussions and orientation activities that are typically done face-to-face with our incoming second-year cohort (Table 1). Since our physical student spaces will be limited or unavailable in fall 2020, we will implement two main tools, Zoom and Miro, for students to interact. Student familiarity with the videoconferencing software Zoom is evident; however, Miro, a platform for online collaborative whiteboarding, will be introduced at the BME Orientation to allow introductions and promote team activities as a beginning step toward building BME community. Miro is a flexible design-oriented space that includes established templates (e.g., Miroverse ${ }^{9}$ ), video embedding and chatting, and presentation modes to promote fun, collaborative, and creative exchanges. Figure 2 depicts an example of a virtual ice breaker activity deployed using the Miro platform. Table 2 provides further details of activities and strategies we have planned that engage the Miro platform.

To encourage an online student-centric social community of second-year BME students, a cadre of additional BME students will help moderate the virtual delivery of several BME experiences. Instructor and faculty presence will be necessary at times (e.g., for course-specific Zoom meetings); however, teaching assistants, PLTL student leaders, and student BME club officers will command experiences that utilize the Miro platform. Altogether, we expect to appoint between five and ten students to monitor these community-building activities throughout the semester. Furthermore, we will promote engagement from upper-level BME undergraduates to drive communication throughout the semester.

\section{REFLECTION}

\section{Spring 2020: BME Student Reflections on Online Learning}

At the completion of the spring 2020 semester, most students in our program lauded our faculty's transition to online instruction; however, many of these students also communicated significant reservations about the virtual learning environment. Perhaps most commonly, students lamented the lack of connection to other students, as demonstrated by reflections from three of our third-year students: 
TABLE 1. Virtual collaboration methods used to promote social community during early BME experiences.

Second-year BME student experience

\section{BME Orientation}

Videos for common program questions

One-minute research faculty videos

Team-based virtual scavenger hunt

\section{Student Collaboration Space ${ }^{8}$}

Study group meeting space

design project workspace,

club information

PLTL (Peer-Led Team Learning) ${ }^{13}$

Weekly problem-solving sessions led by third- or fourth-year BME students

Team Building in Technical Communications

Weekly updates by students between BME and

Technical Communication courses

Ethics: Animal Use in BME Research ${ }^{4}$

Ethics discussion after animal dissection laboratory
Typical delivery

Face-to-face during the first laboratory of the fall semester

Physical room in the engineering building

Face-to-face in laboratory (some will continue face-to-face)

Face-to-face update in lecture

Face-to-face in lecture
Virtual delivery

(Zoom) videoconferencing and breakout sessions

(Miro) team-based scavenger hunt, video repository, etc.

(Miro) study group sign up, mentor-mentee chains, office hour postings

(Zoom) videoconferencing and breakout sessions

(Miro) ice breakers, problem-solving

(Zoom) videoconferencing and breakout sessions

(Miro) icebreakers, updates

(Zoom) videoconferencing and breakout sessions
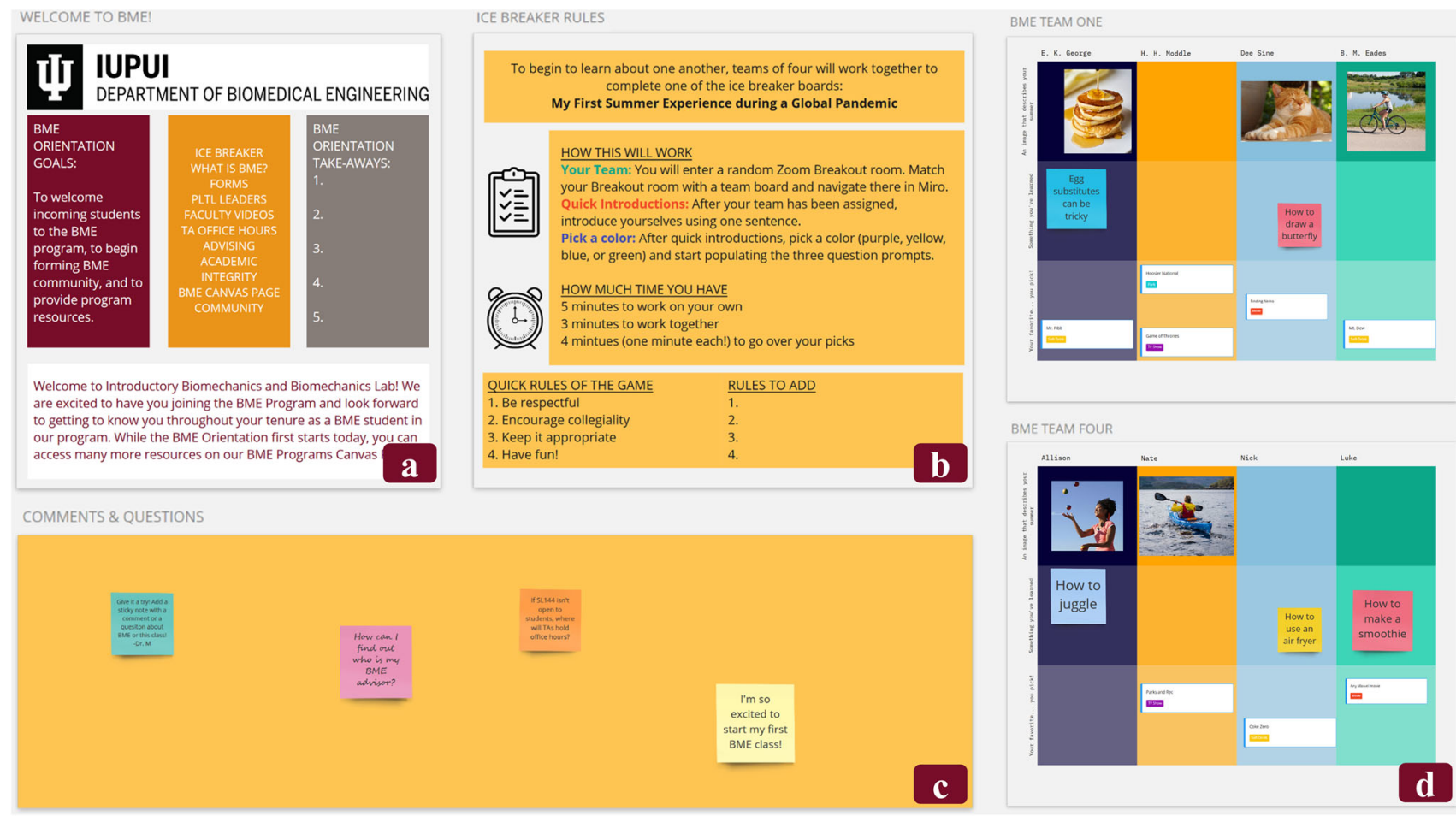

FIGURE 2. Student teams will complete orientation activities using the Zoom and Miro platforms. The Miro board pictured above ${ }^{9}$ will be used for an ice breaker activity, in which each student team meets in a Zoom breakout room while collaborating to complete their assigned Miro frame. The prompts will encourage students to get to know each other and to be creative while designing their team's frame. (a) This frame describes the orientation goals and agenda and provides a place for the group to report key takeaways. (b) This frame provides instructions for the ice breaker activity. (c) This frame is a place for students to post comments and questions. (d) There is one of these frames for each student team, as each team will populate their frame during the ice breaker activity. 
TABLE 2. Summary of proposed Miro activities.

\begin{tabular}{|c|c|}
\hline Miro activity & Description \\
\hline BME Orientation Icebreaker & $\begin{array}{l}\text { This activity (see Fig. 2) aims to help teams of 3-4 students get to know each other during the virtual BME } \\
\text { Orientation event. While in a Zoom breakout room, student teams will work to complete a Miro frame based } \\
\text { on individual student answers to icebreaker questions (e.g., "What image best describes your summer?"). } \\
\text { Students will report out fun or interesting things that they learned about their peers }\end{array}$ \\
\hline $\begin{array}{l}\text { BME Orientation Scavenger } \\
\text { Hunt }\end{array}$ & $\begin{array}{l}\text { This activity will also occur during the virtual BME Orientation event. While in a Zoom breakout room, teams of } \\
3-4 \text { students will work to complete a digital scavenger hunt, seeking out important resources and infor- } \\
\text { mation for undergraduate BME students and posting their findings to a shared Miro board. Prompts will } \\
\text { include: } \\
\text { Where can you find the office hours schedule for BME teaching assistants? } \\
\text { How can you sign up to join a study group for this class? } \\
\text { What steps could you take to get started with undergraduate research? } \\
\text { What requirements must courses meet to constitute a BME concentration)? }\end{array}$ \\
\hline BME Parking Lot & $\begin{array}{l}\text { This ongoing Miro board aims to promote collaboration across years within the BME program. Sophomore } \\
\text { students will be able to post questions about BME courses, life as a BME student, professional opportu- } \\
\text { nities, and other topics to junior and senior BME students. These more senior students can post their } \\
\text { responses to the Miro board and also pose their own questions to the sophomore students }\end{array}$ \\
\hline Study Group Schedules & $\begin{array}{l}\text { A Miro board will be used to organize student study groups. Students will use this board to find and join study } \\
\text { groups based on meeting time, subject, and other factors }\end{array}$ \\
\hline $\begin{array}{l}\text { Technical Communication } \\
\text { Icebreaker }\end{array}$ & $\begin{array}{l}\text { This activity will occur in the (fully-online) Technical Communication course. While in a Zoom breakout room, } \\
\text { teams of 3-4 students will create a Best and Worst Experiences Miro board, with each student listing their } \\
\text { "Best Class l've Ever Taken" and "Worst Class l've Ever Taken." Students will discuss their rationales and } \\
\text { how they can work to make their first BME courses among their best courses }\end{array}$ \\
\hline
\end{tabular}

It was very challenging not to be able to attend to classes and interact with the instructor and the other students.

Studying and working in groups was harder simply because it was not as convenient as meeting at the library after a class.

I did miss working through problems with classmates, and I think that should be facilitated virtually during class periods, or perhaps posted in some sort of whiteboard/forum space so students can collaborate on them outside of the lecture period.

Among all students at our university, "feeling disconnected from other students" was cited as the second most significant challenge related to online learning, after "distractions at home." Further, although 73\% of students reported that they were able to remain connected to their instructors, only $47 \%$ felt they were able to remain connected to other students. ${ }^{5} \mathrm{We}$ recognize that there are no perfect solutions to these problems; students with unreliable internet, unstable home situations, or other challenges will be the most difficult for us to reach. But with time to prepare and primed with an evidence-based approach for tracking sense of community among students, we expect our intentional community-building efforts to pay dividends in fall 2020 and beyond.

\section{Fall 2020: Assessment of Sense of Community Among BME Students}

As described above, we will be making significant efforts in fall 2020 to build community among our new cohort of sophomore students, who are likely to be enrolled in courses that employ inconsistent learning models (e.g., distance, hybrid, face-to-face). We will use a survey adapted from Rovai's Classroom Community Scale $(\mathrm{CCS})^{11}$ to measure sense of community among our sophomore students. The CCS is a brief, validated, and reliable instrument that can be used to interpret social community and learning community in classrooms or other learning environments. Our survey adapts Rovai's Likert-style questions aimed at measuring social community, representing student feelings of community (e.g., sense of belonging); however, we have not included the questions related to learning community. The questions have been reworded to measure social community in our BME program, rather than in a single course. We have added Likert- 
style questions to assess the approachability and usefulness of the technologies employed in the courses (i.e., Miro and Zoom) and two qualitative questions to capture student-identified successes and suggestions in using online platforms for community building. Our adapted survey is attached in the "Appendix".

In order to assess the impact of our interventions on the sense of community in our new sophomore cohort, we will deliver our adapted survey multiple times throughout the fall semester: after four weeks, after eight weeks, and at the completion of the course. Further, we will survey our junior and senior student cohorts at the beginning of the semester to collect baseline data and a point of comparison for our sophomore student cohort. All surveys will be delivered online using the Qualtrics platform, and our study has been granted exemption by the Indiana University Institutional Review Board (IRB) under protocol number 2007679809. We will consider three evaluative questions as we analyze data from our adapted survey:

(1) How does BME student sense of community change over the course of the semester?

(2) How does sense of community among sophomore BME students compare to juniors and seniors in the BME program?

(3) How do BME student scores on the adapted CCS compare to published values describing students in other programs?

By addressing each of these questions using quantitative data collected over the course of one semester from the adapted CCS survey, we will be able to assess the effectiveness of our efforts to build community among our new cohort of BME students.

\section{Looking Forward: Anticipated Benefits Beyond the Pandemic}

Although the transition to online instruction that occurred in spring 2020 was challenging for faculty and students, the experience was likely illuminating for many. The tools and skills relevant to online teaching (video communication, preparation of digital materials, online assessment and evaluation, etc.) can be used to complement traditional teaching methods, rather than replacing them, completely. Given the work we have done to adapt to online instruction and the work we propose to build community in our new student cohort, we anticipate a number of benefits that will continue beyond the COVID-19 pandemic. First, the way in which we orient new students to our undergraduate $\mathrm{BME}$ program will continue to be more engaging and more accessible to Generation Z students. Second, we will continue to be intentional in allowing all of our students to meet each other, allotting time for conversations outside the scope of coursework. Third, our department's faculty will become more comfortable working with an expanded number of educational approaches, gaining experience with digital teaching tools and with engaging with students in a variety of contexts and formats. To conclude, the COVID-19 pandemic has challenged us as BME educators to identify virtual platforms with which we can build social community among incoming BME students and to develop evaluative methods to determine which tools might continue to benefit students, post-pandemic.

\section{AUTHOR CONTRIBUTIONS}

All authors contributed to the conception and design of the activities described in the attached manuscript. The first draft of the manuscript was written by $\mathrm{SH}$ and $\mathrm{SM}$, and the remaining authors provided feedback. All authors read and approved the final manuscript. Furthermore, all authors will be meaningfully involved in the activities proposed in the manuscript.

\section{FUNDING}

None.

\section{CONFLICT OF INTEREST}

The authors declare that they have no competing interest.

\section{ETHICAL APPROVAL}

All methods described in the manuscript that will involve human participants have been granted exemption by the Indiana University Institutional Review Board (IRB) under protocol number 2007679809. Furthermore, the IRB has confirmed that student data included in the manuscript are not subject to IRB approval.

\section{INFORMED CONSENT}

In order to be included as participants in the proposed study, undergraduate students must freely give informed consent to participate. The authors will provide potential participants with a study information sheet that describes the study, including potential risks and benefits. 


\section{APPENDIX}

Adapted Classroom Community Survey ${ }^{11}$

1) Rate your level of agreement with each of the statements below, using the following options: $\begin{array}{lllll}(\mathrm{SA}) \text { Strongly Agree } & \text { (A) Agree } & \text { (N) Neutral } & \text { (D) Disagree } & \text { (SD) Strongly Disagree }\end{array}$

1. I feel that students in the BME Program care about each other

(SA) (A) (N) (D) (SD)

2. I feel connected to others in the BME Program

(SA) (A) (N) (D) (SD)

3. I do not feel a spirit of community

(SA) (A) (N) (D) (SD)

4. I feel that the BME Program is like a family

(SA) (A) (N) (D) (SD)

5. I feel isolated in the BME Program

(SA) (A) (N) (D) (SD)

6. I trust others in the BME Program

(SA)

(A) $\quad$ (N) (D) $\quad(\mathrm{SD})$

7. I feel that I can rely on others in the BME Program

(SA) (A) (N) (D) (SD)

8. I feel that members of the BME Program depend on me

(SA) (A) (N) (D) (SD)

9. I feel uncertain about others in the BME Program

(SA) (A) (N) (D) (SD)

10. I feel confident that others will support me

(SA) (A) (N) (D) (SD)

11. I found activities performed using Miro to be approachable

(SA) (A) (N) (D) (SD)

12. I found Miro activities to be useful toward building community

(SA) (A) (N) (D) (SD)

13. I found activities performed using Zoom to be approachable

(SA)

(A) $\quad(\mathrm{N}) \quad$ (D) $\quad(\mathrm{SD})$

14. I found Zoom activities to be useful toward building community

(SA)

(A) $(\mathrm{N})$

(D) (SD)

2) Do you feel that you have built adequate connections with your peers in the BME Program? If so, please identify specific activities that contributed to these connections. If not, please identify shortcomings of the virtual course activities.

\section{3) Do you have any additional suggestions to promote BME student community online?}

\section{REFERENCES}

${ }^{1}$ Boling EC, Hough M, Krinsky H, Saleem H, Stevens M. Cutting the distance in distance education:perspectives on what promotes positive, online learning experiences. Internet High Educ. 2012;15:118-26.

${ }^{2}$ Cuthbertson W, Falcone A. Elevating engagement and community in online courses. J Libr Inf Serv Distance Learn. 2014;8:216-24.

${ }^{3}$ Dawson S. A study of the relationship between student communication interaction and sense of community. Internet High Educ. 2006;9:153-62.

${ }^{4}$ Hess J, Miller S, Higbee S, Fore G, Wallace J. Empathy and ethical becoming in biomedical engineering education: A mixed methods study of an animal tissue harvesting laboratory. Australas J Eng Educ. https://doi.org/10.1080/ 22054952.2020.1796045.

${ }^{5}$ IUPUI Student COVID-19 Transition Needs Survey.pdf [Internet]. [cited 2020 Jun 18]. Available from: https://irds. iupui.edu/students/student-surveys/covid-19-transition-nee
ds-survey/IUPUI\%20Student\%20COVID-19\%20Transi tion $\% 20$ Needs $\% 20$ Survey.pdf.

${ }^{6}$ Johnston J, Killion J, Oomen J. Student satisfaction in the virtual classroom. Internet $\mathrm{J}$ Allied Health Sci. Pract. 2005;3.

${ }^{7}$ Linsenmeier RA, Saterbak A. Fifty years of biomedical engineering undergraduate education. Ann Biomed Eng. 2020;48:1590-615.

${ }^{8}$ Miller S, Higbee S. Embedding and assessing engineering design curriculum with course outcomes and learning spaces in mind. Frontiers in Education - Special Session. Uppsala, Sweden; 2020.

${ }^{9}$ Miroverse | Miro Community Templates Gallery. https:// miro.com/miroverse/. Accessed 22 June 2020.

${ }^{10}$ Rovai AP. Sense of community, perceived cognitive learning, and persistence in asynchronous learning networks. Internet High Educ. 2002;5:319-32.

${ }^{11}$ Rovai AP. Development of an instrument to measure classroom community. Internet High Educ. 2002;5:197211. 
${ }^{12}$ Tinto V. Leaving college: rethinking the causes and cures of student attrition. Chicago: University of Chicago Press; 1987.

${ }^{13}$ Varma-Nelson P, Banks J. PLTL: tracking the trajectory from face-to-face to online environments. Trajectories Chem Educ Innov Reform. https://doi.org/10.1021/bk-201 3-1145.ch007; 2013.

${ }^{14}$ Vesely P, Bloom L, Sherlock J. Key elements of building online community: comparing faculty and student perceptions. 2007;3:13.
${ }^{15}$ Yilmaz R. Knowledge sharing behaviors in e-learning community: exploring the role of academic self-efficacy and sense of community. Comput Hum Behav. 2016;63:373-82.

Publisher's Note Springer Nature remains neutral with regard tojurisdictional claims in published maps and institutional affiliations. 